\title{
Congenital Malformations and Developmental Anomalies of the Lung
}

\author{
Pooja Abbey $\cdot$ Mahender K. Narula . \\ Rama Anand
}

Published online: 12 September 2014

(C) Springer Science+Business Media New York 2014

\begin{abstract}
Congenital malformations of the lung are a group of diverse, yet related, abnormalities which may involve the lung parenchyma, pulmonary vasculature, or a combination of both. They may be detected in fetal life, produce severe symptoms during infancy, or may not manifest symptomatically until adulthood. The goal of imaging is to demonstrate the various components of the malformation, to facilitate appropriate management. This article discusses the spectrum of congenital and developmental lung anomalies, their etio-pathogenesis, role of various imaging modalities, and characteristic radiological findings.
\end{abstract}

Keywords Congenital lung malformations - MDCT ·

Focal hyperlucency - Pulmonary vascular malformations . Congenital lobar hyperinflation · Bronchial atresia .

Congenital pulmonary airway malformation

\section{Introduction}

Congenital and developmental abnormalities of the lung encompass a heterogeneous group of conditions, which exhibit myriad differences, and yet have many features in

This article is part of topical collection on CT Pulmonary Embolus and Diffuse Lung Disease.

P. Abbey $(\bowtie) \cdot$ M. K. Narula $\cdot$ R. Anand

Department of Radio-diagnosis, Lady Hardinge Medical College

and Smt. Sucheta Kriplani Hospital, New Delhi, India

e-mail: pooja_abbey@yahoo.co.in

M. K. Narula

e-mail: narulamk@gmail.com

R. Anand

e-mail: rama_home@yahoo.com common. They may involve different components of the lung - the parenchyma/airway component, arterial supply and/or venous drainage. Congenital lung malformations (CLM) have a reported annual incidence of 30-42 cases per 100,000 population $[1,2]$. With emergence of prenatal ultrasonography (US), many cases are now detected in utero. The modes of clinical presentation vary widelyfrom respiratory distress at birth to incidental detection in an asymptomatic adult.

This article addresses basic concepts regarding the spectrum of CLM, etio-pathogenesis, approach to imaging, radiological findings, and recommended nomenclature and classification.

\section{Spectrum of Congenital Lung Malformations}

CLM can show predominantly parenchymal or predominantly vascular anomalies, or a combination of both (Table 1).They occur as a continuum of abnormalities [3], with the presence of lung parenchymal abnormality and normal vasculature on one hand (in congenital pulmonary airway malformation-CPAM, and congenital lobar hyperinflation-CLH) and abnormal vasculature in the absence of parenchymal abnormality on the other hand (pulmonary arterio-venous malformations-AVMs). Many cases have features overlapping between two or more conditions ('hybrid' lesions) - for instance CPAM-like changes in an area of 'sequestered' lung [4, 5].

\section{Etiology and Pathogenesis}

For a long time, the most widely accepted theory of etiopathogenesis was that of defective budding, separation, and 
Table 1 Spectrum of congenital lung malformations [21, 24]

\begin{tabular}{|c|c|}
\hline \multirow[t]{5}{*}{$\begin{array}{l}\text { Predominantly parenchymal } \\
\text { abnormalities }\end{array}$} & $\begin{array}{l}\text { Congenital lobar hyperinflation } \\
\text { (CLH) }\end{array}$ \\
\hline & Congenital bronchial atresia \\
\hline & $\begin{array}{l}\text { Congenital pulmonary airway } \\
\text { malformation (CPAM) }\end{array}$ \\
\hline & $\begin{array}{l}\text { Foregut duplication cysts } \\
\text { (bronchogenic cyst) }\end{array}$ \\
\hline & $\begin{array}{l}\text { Airway abnormalities (laryngeal } \\
\text { atresia/stenosis, tracheal atresia/ } \\
\text { stenosis) }\end{array}$ \\
\hline \multicolumn{2}{|l|}{$\begin{array}{l}\text { Predominantly vascular } \\
\text { abnormalities involving }\end{array}$} \\
\hline Pulmonary artery & $\begin{array}{l}\text { Pulmonary agenesis-aplasia- } \\
\text { hypoplasia complex, proximal } \\
\text { interruption of pulmonary artery, } \\
\text { pulmonary artery sling }\end{array}$ \\
\hline Pulmonary vein & $\begin{array}{l}\text { Pulmonary vein stenosis, venous } \\
\text { varix }\end{array}$ \\
\hline $\begin{array}{l}\text { Both pulmonary artery and } \\
\text { vein }\end{array}$ & $\begin{array}{l}\text { Pulmonary arterio-venous } \\
\text { malformation (AVM) }\end{array}$ \\
\hline \multirow[t]{2}{*}{$\begin{array}{c}\text { Combination of parenchymal } \\
\text { and vascular abnormalities }\end{array}$} & $\begin{array}{r}\text { Pulmonary sequestration } \\
\text { (intralobar, extralobar) }\end{array}$ \\
\hline & $\begin{array}{l}\text { Scimitar syndrome/hypogenetic } \\
\text { lung syndrome }\end{array}$ \\
\hline
\end{tabular}

differentiation of primitive foregut structures $[3,6,7]$. Langston [8] proposed that many lesions could be explained to occur as a result of airway obstruction leading to secondary pulmonary dysplastic changes. Differences in the level, completeness, and timing of the obstructive event were postulated to result in various anomalies. The etiological role of vascular abnormality has also been suggested. The molecular mechanisms which regulate normal lung development and show altered patterns of expression in CLM have been the subject of research [9-11]. Familial association has also been reported [12]. It is likely that multiple such factors act in concert.

\section{Approach to Imaging}

US is the primary imaging modality for fetal screening. It provides valuable information about the presence and size of a focal lung lesion (lesion volume) [13], mass effect, associated hydrops fetalis, lung hypoplasia, and other organ malformations, all of which affect the prognosis and management $[14,15 \bullet]$. Fetal magnetic resonance (MR) imaging is helpful-in select cases-for lung volume quantification, in addition to evaluation of the lesion [16*, $17,18]$.

Chest radiograph is the first line of investigation in a symptomatic child. Congenital anomalies may exhibit varied appearances [19-21]—like focal hyperlucency, presence of fluid or air-filled cystic (or solid-appearing) lesions, vascular anomaly, airway abnormality or thoracic asymmetry. Radiographic differential diagnosis of few common CLM is given in Table 2. Radiographic findings should be carefully interpreted, compared with previous radiographs, and, when necessary, should prompt further evaluation using cross-sectional imaging techniques like US, multidetector-computed tomography (MDCT) or MR imaging.

US may be very useful in newborns and infants. It is radiation-free, and focal pulmonary lesions can be well assessed. Doppler sonography delineates vascular supply. High-resolution linear transducers are used, and transsternal, parasternal or intercostal approaches may be utilized $[22,23]$. However, the US has limited utility in older children.

The benefits of fast speed, high spatial resolution and volumetric imaging with multiplanar and 3D reconstructions make MDCT the technique of choice for evaluation of CLM [21, 24]. It enables high-resolution images of the pulmonary parenchyma, with simultaneous evaluation of the vascular anatomy using $\mathrm{CT}$ angiography. The major limitation is radiation exposure. In the pediatric patient, there should be strict adherence to the as low as reasonably achievable (ALARA) principle [25, 26]. Exposure factors (kilovoltage and milliamperage) should be titrated against the age and weight of the child. Evaluation in a single phase (post-contrast) usually suffices, and multiphasic CT examinations should be avoided.

MR imaging scores over MDCT as it does not involve exposure to radiation. It has excellent contrast resolution. However, its spatial resolution is inferior to CT and details of lung parenchyma are not well assessed [21]. Scan times are long. MR imaging may be utilized in select cases of predominantly solid and vascular CLMs and as a follow-up imaging technique.

Digital subtraction angiography (DSA) is not usually required for diagnostic purposes; however, may be performed prior to endovascular embolization for vascular anomalies like pulmonary AVMs.

\section{Parenchymal (Non-vascular) Anomalies}

\section{Congenital Lobar Hyperinflation}

CLH was previously known as congenital lobar emphysema, but the term 'emphysema' implies destruction of alveoli, which does not occur in this condition. Though no cause is identifiable in approximately half the cases, this condition is thought to result from bronchial narrowing due to intrinsic (cartilage) abnormality or extrinsic compression, leading to progressive over-inflation due to a "ball- 
Table 2 Common locations and radiographic differential diagnosis of few common CLM

\begin{tabular}{|c|c|c|}
\hline Malformation & Common location & $\begin{array}{l}\text { Radiographic } \\
\text { differential diagnosis }\end{array}$ \\
\hline \multirow[t]{2}{*}{$\begin{array}{l}\text { Congenital lobar } \\
\text { hyperinflation } \\
(\mathrm{CLH})\end{array}$} & $\begin{array}{l}\text { Left upper lobe } \\
(42 \%) \text {, middle lobe } \\
(35 \%) \text {, right upper } \\
\text { lobe }(21 \%) \\
\text { (uncommon in lower } \\
\text { lobes-<1\%) }\end{array}$ & $\begin{array}{l}\text { Loculated } \\
\text { pneumothorax }\end{array}$ \\
\hline & & $\begin{array}{l}\text { Congenital pulmonary } \\
\text { airway malformation } \\
\text { (CPAM) } \\
\text { Pneumatocele }\end{array}$ \\
\hline \multirow{5}{*}{$\begin{array}{l}\text { Congenital } \\
\text { pulmonary } \\
\text { airway } \\
\text { malformation } \\
\text { (CPAM) }\end{array}$} & No lobar predilection & CLH \\
\hline & $\begin{array}{l}\text { Usually involves single } \\
\text { lobe }\end{array}$ & $\begin{array}{l}\text { Loculated } \\
\text { pneumothorax }\end{array}$ \\
\hline & $\begin{array}{l}\text { Bilobar/bilateral } \\
\text { involvement } \\
\text { uncommon }(<5 \%)\end{array}$ & $\begin{array}{l}\text { Pulmonary } \\
\text { sequestration (if } \\
\text { located in lower } \\
\text { lobe) }\end{array}$ \\
\hline & & $\begin{array}{l}\text { Congenital } \\
\text { diaphragmatic hernia } \\
\text { (if located in lower } \\
\text { lobe) }\end{array}$ \\
\hline & & $\begin{array}{l}\text { Intrapulmonary } \\
\text { bronchogenic cyst/ } \\
\text { infected hydatid cyst/ } \\
\text { lung abscess (if } \\
\text { infected) }\end{array}$ \\
\hline \multicolumn{3}{|l|}{$\begin{array}{l}\text { Pulmonary } \\
\text { sequestration }\end{array}$} \\
\hline \multirow[t]{2}{*}{$\begin{array}{l}\text { Intralobar } \\
\text { sequestration }\end{array}$} & $\begin{array}{l}98 \% \text { cases occur in } \\
\text { lower lobes } \\
\text { (left }>\text { right), } \\
\text { typically in posterior } \\
\text { basal segment }\end{array}$ & Pneumonia \\
\hline & $\begin{array}{l}\text { Radiographic } \\
\text { appearances are } \\
\text { variable }\end{array}$ & $\begin{array}{l}\text { Lung cyst-CPAM, } \\
\text { bronchogenic cyst } \\
\text { Lung mass }\end{array}$ \\
\hline $\begin{array}{l}\text { Extralobar } \\
\text { sequestration }\end{array}$ & $\begin{array}{l}\text { Classically in the } \\
\text { posterior } \\
\text { costodiaphragmatic } \\
\text { sulcus between left } \\
\text { lower lobe and } \\
\text { hemidiaphragm } \\
\text { (63-77\% cases) }\end{array}$ & $\begin{array}{l}\text { Basal atelectasis } \\
\text { Focal eventration of } \\
\text { diaphragm }\end{array}$ \\
\hline $\begin{array}{l}\text { Bronchogenic } \\
\text { cyst }\end{array}$ & $\begin{array}{l}\text { Mediastinum } \\
\text { (65-90\% cases) } \\
\text { Intrapulmonary } \\
(10-35 \%) . \text { More } \\
\text { common in lower } \\
\text { lobes }\end{array}$ & $\begin{array}{l}\text { Mediastinal } \\
\text { lymphadenopathy } \\
\text { Round pneumonia } \\
\text { Hydatid cyst } \\
\text { Lung mass } \\
\text { Infected CPAM/ } \\
\text { hydatid cyst (if } \\
\text { infected) }\end{array}$ \\
\hline
\end{tabular}

valve' effect. It most commonly affects the left upper lobe ( $42 \%$ cases), followed by the middle lobe $(35 \%)$ and the right upper lobe $(21 \%)$ [27, 28]. The lower lobes are uncommonly involved ( $<1 \%$ cases). Patients present soon after birth with respiratory distress, and presentation after the age of 6 months is uncommon. CLH may occur in a classic form (with normal/reduced number of alveoli) or polyalveolar form (increased number of alveoli).

Focal hyperlucency is usually evident on radiographs, with mediastinal shift (Fig. 1). MDCT enables accurate diagnosis by demonstrating an area of hyperinflation with attenuated bronchovascular markings within. Symptomatic patients are managed surgically (lobectomy), while those without symptoms may be managed conservatively [29].

\section{Congenital Bronchial Atresia}

Bronchial atresia (BA) refers to focal obliteration of a lobar, segmental or sub-segmental bronchus, with normal development of distal airways [24]. Inspissation of secretions in the bronchus distal to the atresia forms a bronchocele. Opening of collateral pathways often leads to airtrapping [27•]. Most cases are asymptomatic. The upper lobe bronchi are commonly involved, with most frequent involvement of the segmental apico-posterior bronchus of left upper lobe [30]. CT is the most sensitive modality for diagnosis, and demonstrates the bronchocele as a branching, tubular opacity, often with air-trapping in the adjacent lung (Fig. 2).

Bronchial atresia may also occur as a component of other CLMs, like PS, CPAM [8].

\section{Congenital Pulmonary Airway Malformations}

CPAMs, earlier known as congenital cystic adenomatoid malformations (CCAMs), result from disorganized proliferation of primary bronchioles, which communicate with the bronchial tree. $95 \%$ cases involve a single lobe, without any lobar predilection [27•]. Bilateral lesions are uncommon. CPAMs have been classified by Stocker et al. [31] into three types - the most common (type 1) shows single/multiple large cysts, size $>2 \mathrm{~cm}$ (Fig. 3). Type 2 lesions consist of multiple smaller cysts $(<2 \mathrm{~cm})$, whereas type 3 lesions (the least common) comprise of microcysts $(<0.5 \mathrm{~cm})$ and have a pseudo-solid appearance on imaging. An updated classification by Stocker [32] describes two additional types-type 0 results from acinar dysgenesis or dysplasia of large airways and is incompatible with life, whereas type 4 lesions have large cysts of distal acinar (peripheral) origin [21]. 


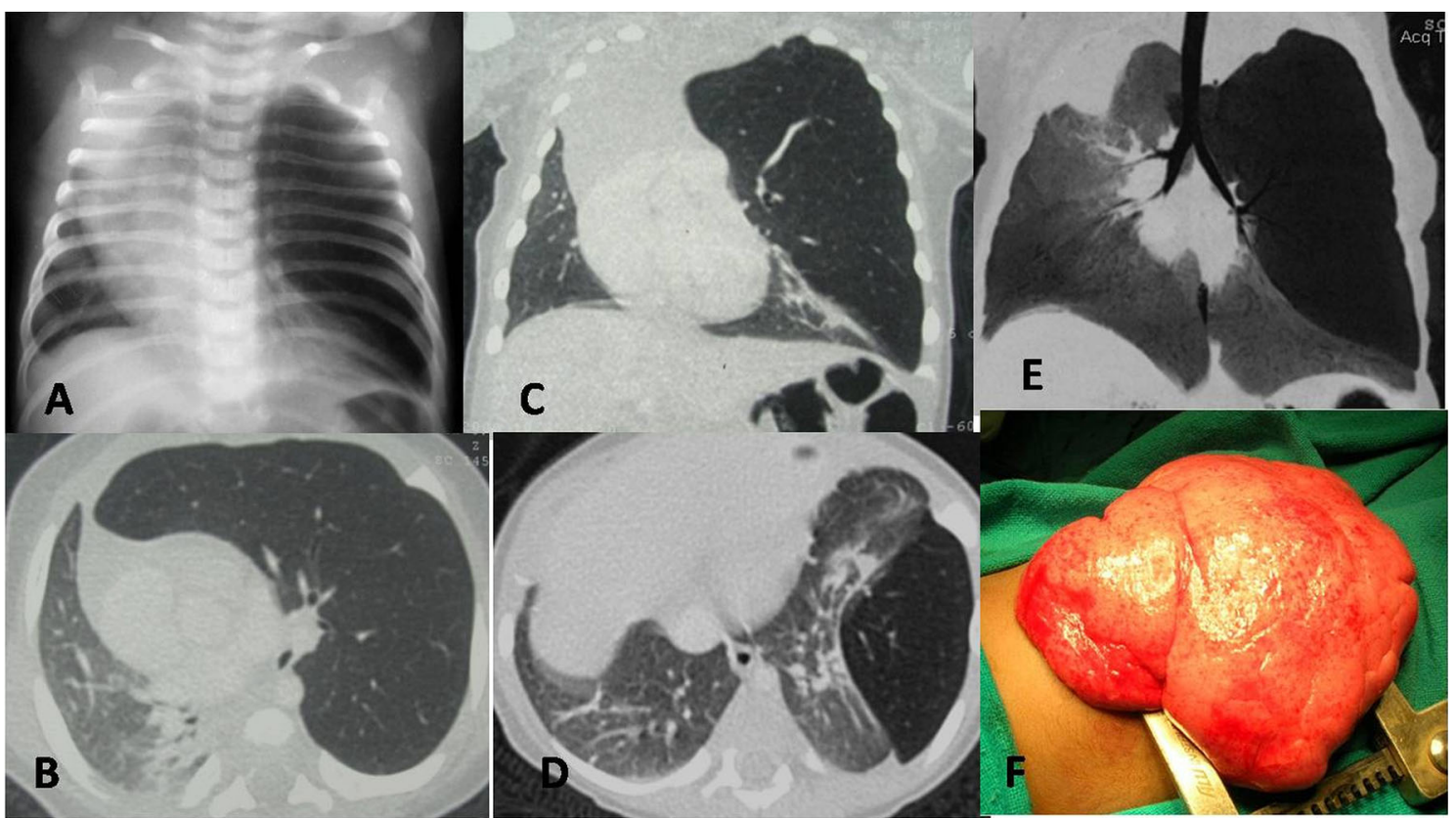

Fig. 1 Congenital lobar hyperinflation in a 45-day-old male child with acute onset respiratory distress. Chest radiograph (a) reveals a focal hyperlucency in the left upper and mid zones, with mass effect and mediastinal displacement to the right. CT Chest, lung window, axial (b, d) and coronal (c) images, along with minimum intensity projection (MinIP) image (e) reveal an over-inflated left upper lobe, showing attenuated bronchovascular markings. Intra-operative photograph (f) confirms the findings
Imaging appearances depend upon the type and size of the lesion, and the presence or absence of superadded infection. Radiographs may demonstrate only a hyperlucent lesion (Fig. 3), which, depending on its location, may mimic congenital lobar hyperinflation, pneumothorax, or congenital diaphragmatic hernia (Table 2). On radiographs, infected type 1 CPAMs appear similar to secondarily infected hydatid or bronchogenic cysts (Fig. 4), and may mimic a lung abscess. MDCT depicts air-containing lung parenchymal lesions comprising of cysts of variable sizes (Figs. 3, 5), and may show cyst wall thickening and airfluid levels within infected CPAMs (Fig. 5). Large lesions usually present in infancy with respiratory distress. Smaller lesions may be detected in older children, incidentally or in association with recurrent chest infections. 'Hybrid' lesions, which overlap with pulmonary sequestration (PS), may demonstrate a systemic arterial supply (Fig. 6).

CPAMs are increasingly being detected on prenatal US. They are seen as cystic or solid-appearing lung masses. Their natural course is variable, and most microcystic lesions plateau in their growth by 26-28 weeks' gestation [15•]. Up to $15 \%$ lesions regress in size and may 'disappear' on US, though they can be identified on postnatal CT [33]. Associated hydrops is a harbinger of fetal demise, and an indication for fetal therapy [15•]. Large macrocystic CPAMs have been successfully treated with throacoamniotic shunting [34]. Maternal betamethasone therapy is useful in predominantly solid lesions with hydrops [35]. Patients who do not respond may be candidates for fetal surgery (at $<30$ weeks). CPAM resection may be planned

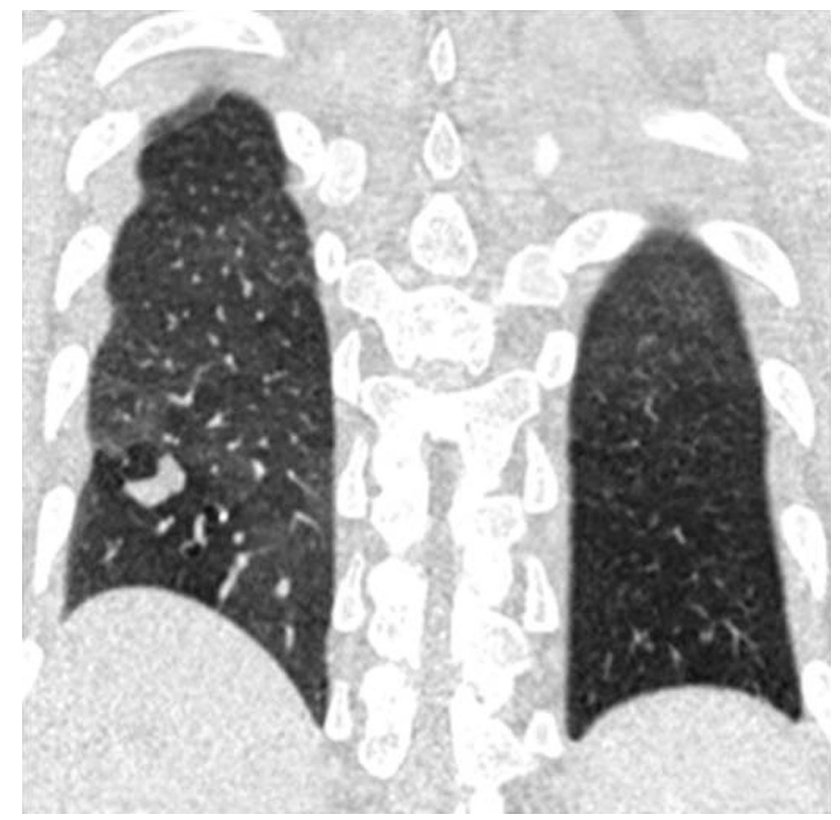

Fig. 2 Bronchial atresia in an 18-year-old girl being evaluated for fever. CT chest, coronal image (lung window) reveals a bronchocele involving the lateral segmental bronchus of the right lower lobe with associated air-trapping (patient was managed conservatively) 


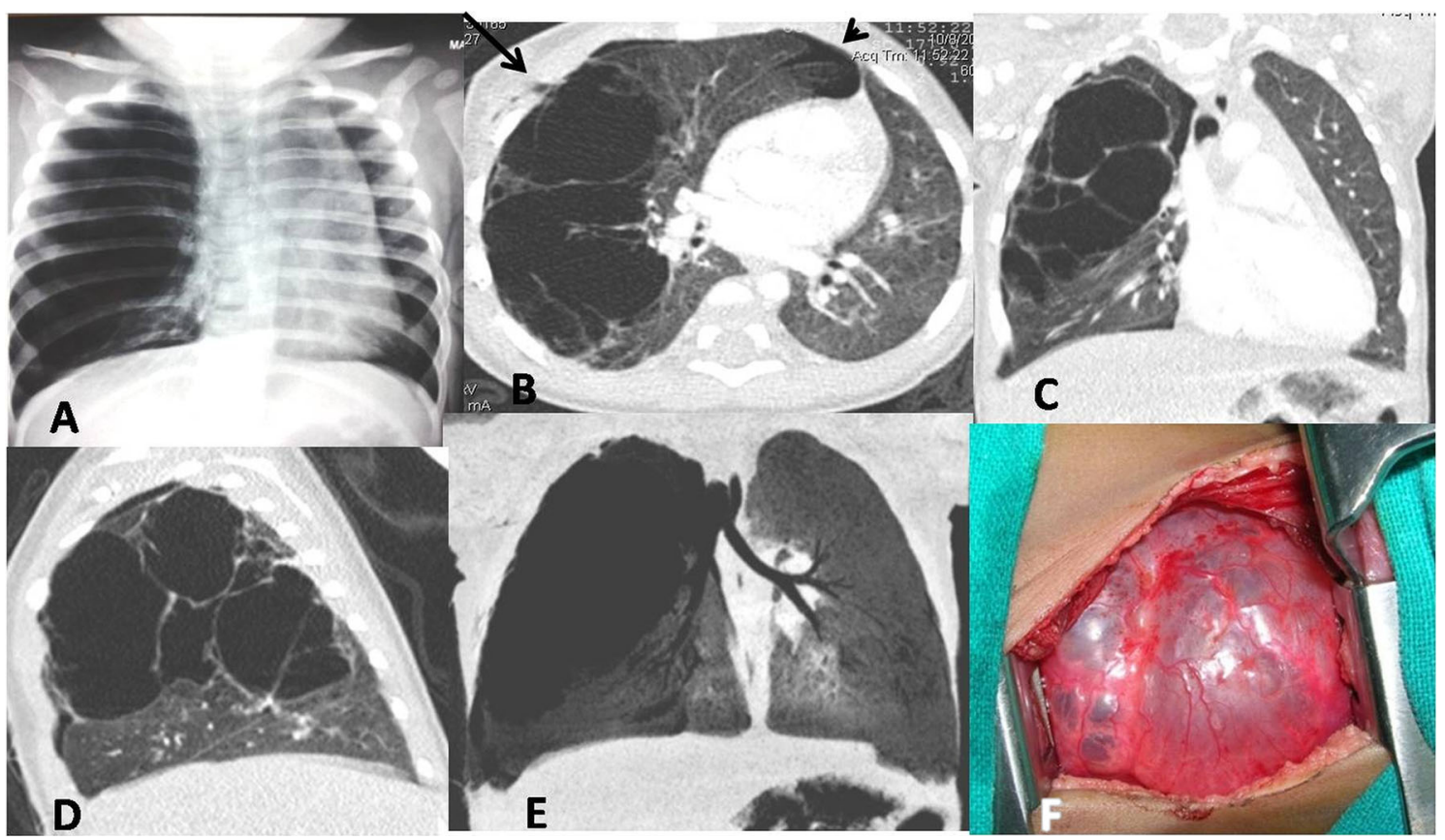

Fig. 3 A 6-month-old child with respiratory distress. Chest radiograph (a) shows a focal hyperlucency in right upper/mid zones, with mass effect. This was interpreted as a pneumothorax, and chest tube was inserted at a primary care center. Symptoms did not significantly improve. Subsequent CT chest, lung window, axial (b), coronal

at the time of delivery by EXIT (ex utero intra partum) procedure [15•].

Expectant management is appropriate for most nonhydropic fetuses. Postnatal management of symptomatic lesions is surgical resection. The management of asymptomatic lesions, however, is controversial [36-38], most notably as CPAMs are associated with increased risk of malignancy, including pleuropulmonary blastoma and bronchioalveolar carcinoma [36॰]. Further research is (c) and sagittal (d) images, and coronal MinIP image (e) reveals a type 1 CPAM in the right upper lobe, with multiple cysts, many larger than $2 \mathrm{~cm}$. A small right pneumothorax (arrowhead in b) is also seen, along with chest tube tract (black arrow). Intraoperative photograph (f) shows the multi-cystic lesion

needed into the merits of a surgical versus conservative approach to asymptomatic cases.

\section{Bronchogenic Cysts}

Bronchogenic cysts are a part of the spectrum of foregut duplication cysts (which also includes enteric and neurenteric cysts) and result from abnormal airway budding/ branching during fetal life. They are commonly located in

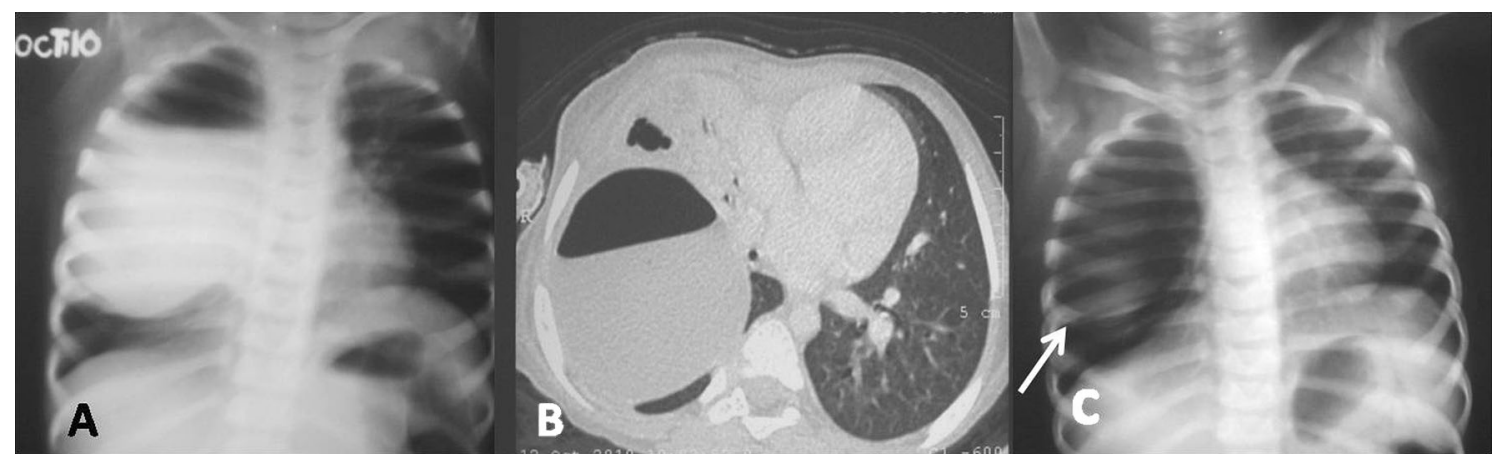

Fig. 4 A 3 year-old-child presented with fever and cough since 1 week, with a history of two past episodes of chest infection. Frontal chest radiograph (a) reveals a large well-defined cystic lesion in the right lung with an air-fluid level. CT chest, lung window, (b) confirms its intrapulmonary location and shows adjacent collapse- consolidation. A previous chest radiograph of the same child, done 6 months earlier (c), shows a thin walled air-filled lung cyst (arrow). Diagnosis of an infected lung cyst was made. Surgery and histopathology confirmed an infected type 1 CPAM 


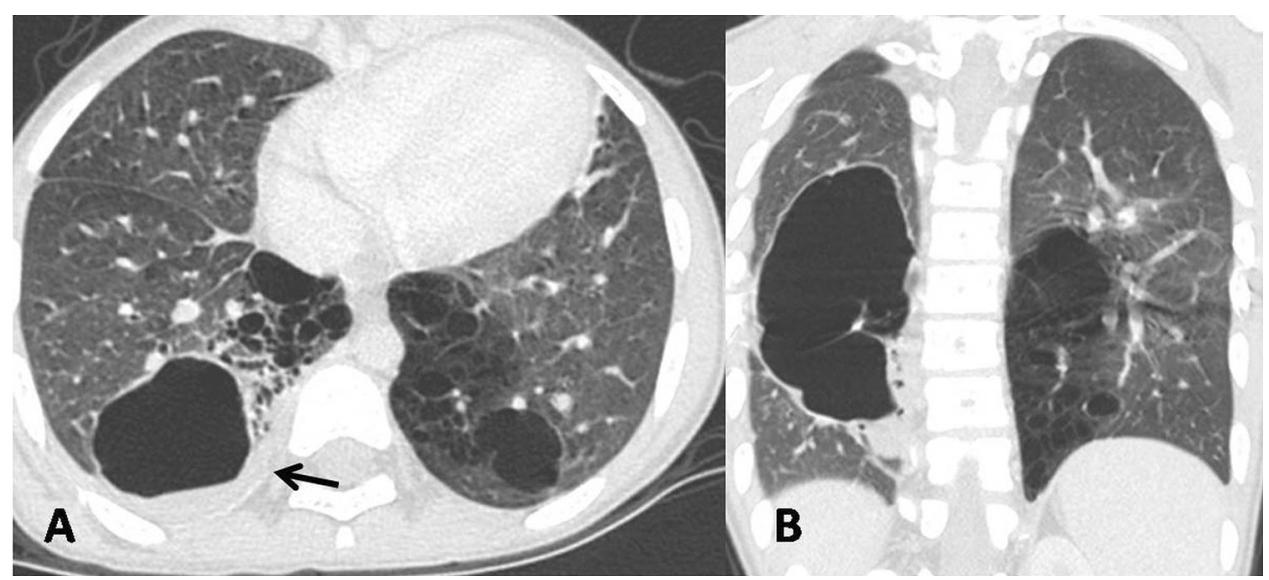

Fig. 5 A 6-year-old girl with bilateral CPAM presented with difficulty in breathing. CT chest, lung window, axial (a) and coronal (b) images reveal multi-cystic lesions in lower lobes of both lungs. The right lung lesion (containing cysts $>2 \mathrm{~cm}$-type $1 \mathrm{CPAM}$ ) shows

the mediastinum-subcarinal, hilar or paratracheal regions (65-90\% cases) [24]. They may present with mass effect on the esophagus or airway (do not usually communicate with the airway). Due to proteinaceous content, their $\mathrm{CT}$ attenuation may be higher than water in $50 \%$ cases. thick walls and an air-fluid level (arrow). This lesion was infected and was surgically resected. The left lung lesion had smaller cysts ( $<2 \mathrm{~cm}$ - type $2 \mathrm{CPAM}$ ), and was managed conservatively

Less commonly, cysts may be intrapulmonary, commonly in lower lobes. These cases may have an airway communication, and may present with infection, with radiological findings resembling those of infected CPAMs (Fig. 7). Final diagnosis is established on pathology by demonstration of respiratory epithelium [39].

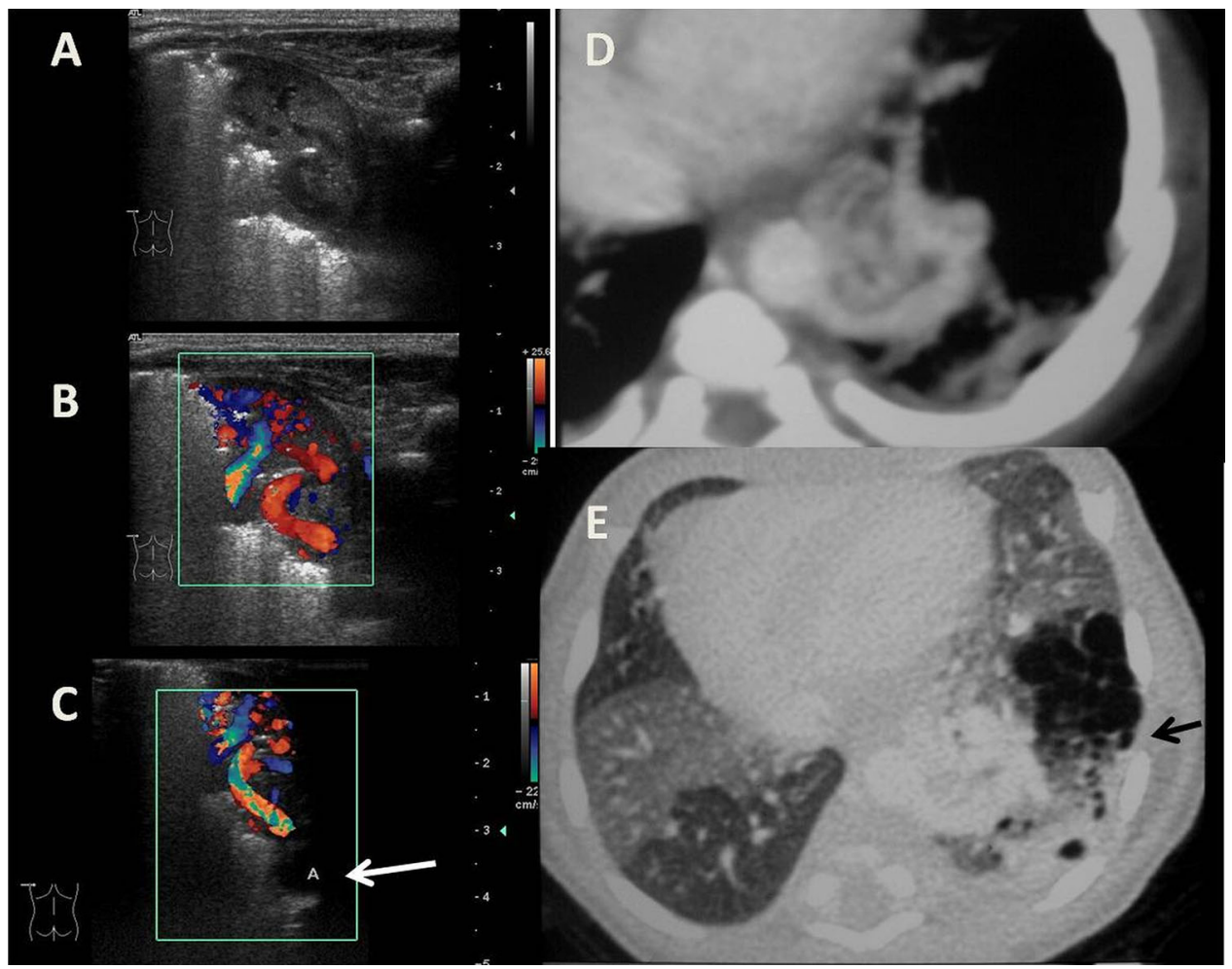

Fig. 6 An asymptomatic newborn had been diagnosed with a left lung 'mass' on prenatal US. Postnatal grayscale US (a) and doppler (b, c) images reveal left lower lobe consolidation, and an aberrant vessel arising from the aorta (white arrow in image c). CECT chest, axial section, mediastinal window (d) demonstrates the supplying vessel (systemic artery), and axial lung window image (e) shows an area of consolidation in left lower lobe, along with multiple small airfilled cystic lesions (arrow), suggestive of a component of CPAM. A 'hybrid' lesion - sequestration with CPAM — was proven on postoperative histopathology 


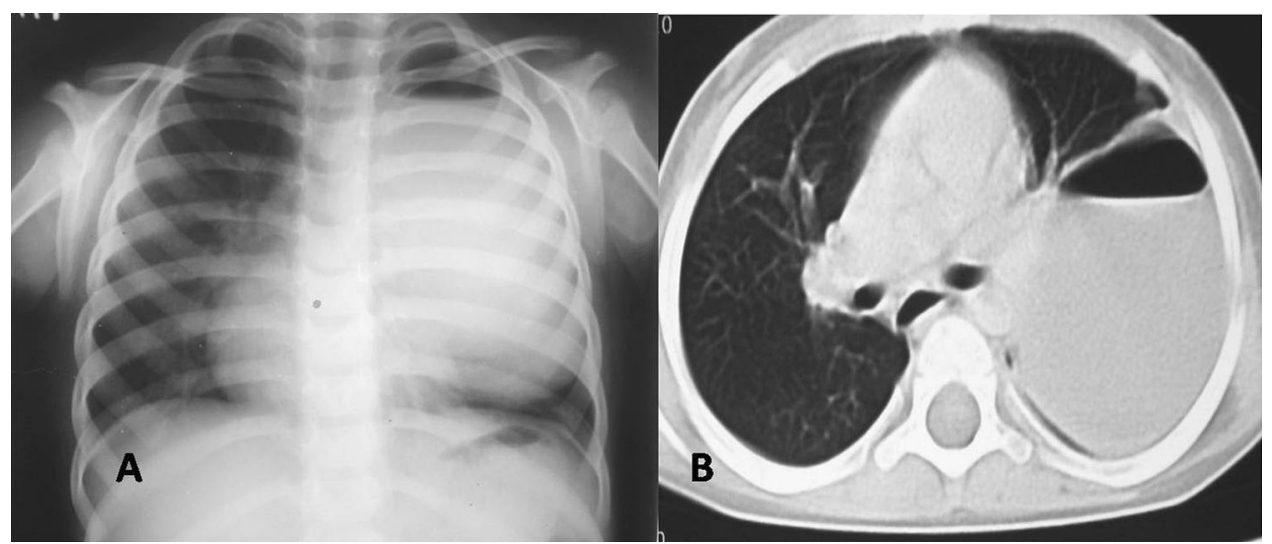

Fig. 7 A 2-year-old boy presented with fever of 2 weeks' duration. Frontal chest radiograph (a) reveals a large cyst containing an airfluid level in the left lung, also seen on chest CT, lung window (b).

\section{Airway Anomalies}

Congenital high airway obstruction syndrome (CHAOS) is a rare anomaly caused by laryngeal or tracheal atresia [40].
This was an infected lung cyst, confirmed at surgery and histopathology (which revealed respiratory epithelium). Final diagnosis was intrapulmonary bronchogenic cyst

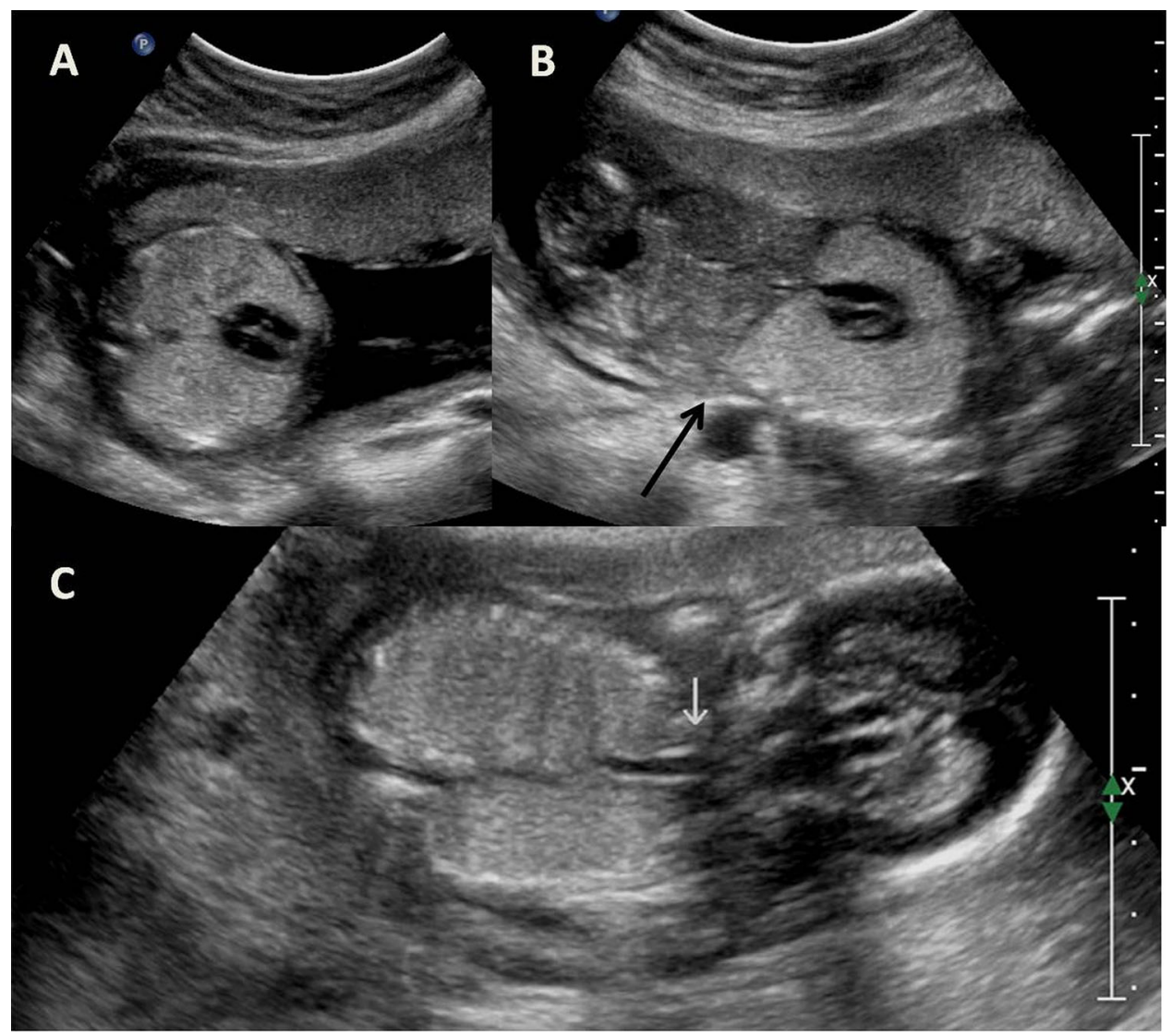

Fig. 8 Prenatal US of a 19-week-old fetus. Axial (a) and coronal oblique (b) scans through the fetal thorax reveal enlargement and increased echogenicity of both lungs, with mild compression of the fetal heart and flattening of diaphragm (black arrow). Coronal oblique
Pulmonary hyperplasia develops secondary to obstruction to the outflow of fetal lung fluid [41]. Prenatal US findings are characteristic, with enlargement and increased echogenicity of both lungs, inversion of hemidiaphragms and section through the fetal neck/upper chest (c) reveals a dilated, fluidfilled trachea (white arrow). Diagnosis of congenital high airway obstruction syndrome (CHAOS) was made, and subsequent fetal autopsy confirmed laryngeal atresia 
compression of the fetal heart (Fig. 8). Distal to the site of obstruction, fluid-filled dilated trachea and bronchi are seen. This condition is fatal.

\section{Vascular Anomalies}

Pulmonary Agenesis-Aplasia-Hypoplasia Complex

Pulmonary agenesis (complete absence of lung tissue, bronchus and pulmonary artery) is part of a spectrum of pulmonary underdevelopment which includes pulmonary aplasia (absence of lung and pulmonary artery with rudimentary main bronchus) and hypoplasia (hypoplastic pulmonary artery and bronchus with variable amount of lung tissue). Abnormal blood flow in the dorsal aortic arch during fetal development has been suspected to play a role in pathogenesis [27•]. Patients may present as newborns with respiratory or feeding difficulty, or may remain asymptomatic till adulthood. Pulmonary agenesis, aplasia, and hypoplasia appear similar on chest radiographs, which reveal a small opaque hemithorax with ipsilateral shift of mediastinum. MDCT can differentiate these conditions by demonstration of hypoplastic bronchus and/or pulmonary artery (Fig. 9). Congenital anomalies involving other organ systems are often associated, and influence the prognosis. Bilateral pulmonary agenesis or aplasia proves fatal.

\section{Agenesis of Pulmonary Artery}

Agenesis or proximal interruption of the pulmonary artery is a rare anomaly which occurs due to embryological failure of development of the proximal portion of the main pulmonary artery, with presence of pulmonary artery at the hilum and distally. It is more common on the right side, and leads to lung hypoplasia.

\section{Pulmonary Artery Sling}

Pulmonary artery sling is a vascular anomaly in which the left pulmonary artery has an aberrant origin from the

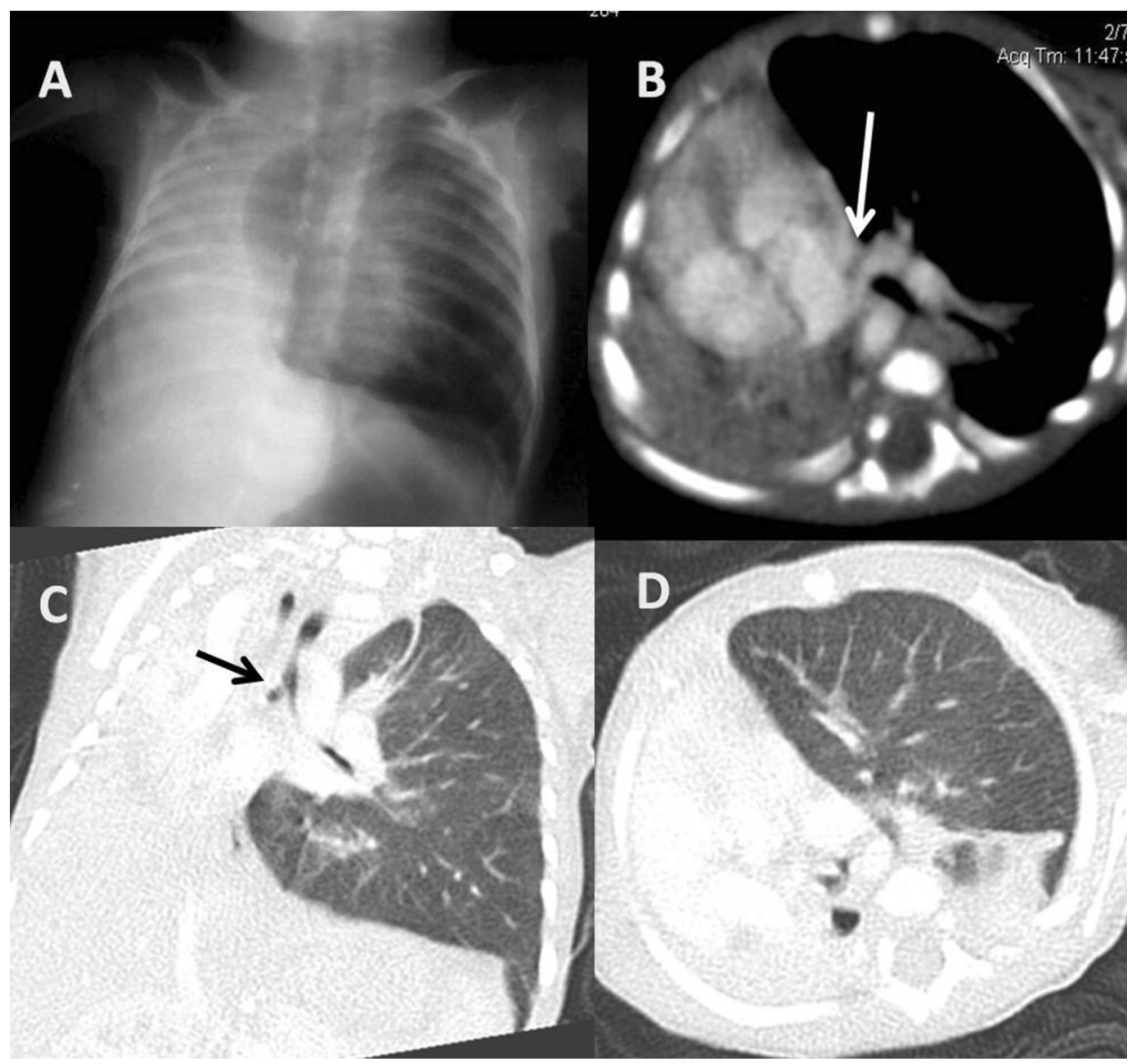

Fig. 9 A 3 month-old-female child presented with respiratory distress. Frontal chest radiograph (a) reveals a small, opaque right hemithorax with ipsilateral shift of mediastinal structures. CT chest, axial mediastinal window (a), reveals a hypoplastic right pulmonary artery (white arrow). Lung window sections in the coronal (c) and axial (d) planes reveal a rudimentary right bronchus (black arrow) and a small amount of right lung parenchyma. This was a case of hypoplasia of right lung 
Fig. 10 A pulmonary AVM detected on CT chest of a 60-year-old woman being evaluated for tubercular lymphadenopathy. Axial MIP sections $(\mathbf{a}, \mathbf{b})$ reveal a cluster of abnormal, dilated pulmonary vessels in the left lower lobe. Coronal MIP sections (c d) reveal a feeding artery arising from the left lower lobar pulmonary artery (arrowheads) and a vein draining the lesion via the inferior pulmonary vein (long white arrows) into the left atrium

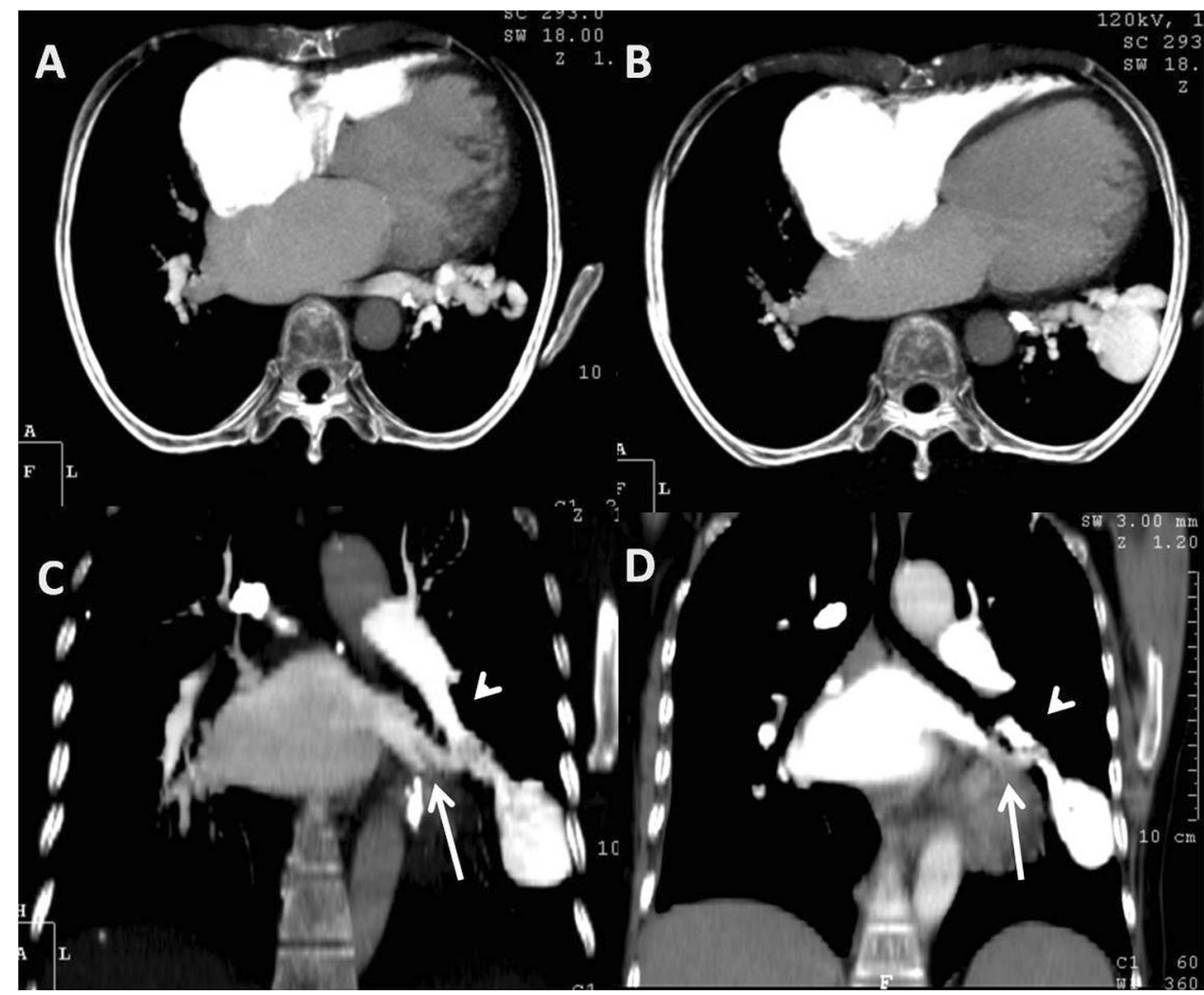

proximal right pulmonary artery, and crosses the mediastinum between the trachea and the esophagus, thus forming a 'sling' around the distal trachea [27•]. It may result in tracheo-bronchial compression. There are two types of pulmonary artery sling-type 1 , in which carina is normal in position (T4-5), and type 2, which is associated with a low-lying (T6) carina and horizontal course of main bronchi. Type 2 lesions are often associated with longsegment tracheal stenosis, bridging bronchus, horseshoe lung, lung agenesis, and congenital heart disease.

\section{Pulmonary Vein Stenosis}

This condition usually occurs in association with congenital heart disease or anomalous pulmonary venous return [42]. It can also occur in isolation, usually at the veno-atrial junction.

\section{Pulmonary Varix}

A pulmonary varix is an enlarged pulmonary vein in the absence of a feeding artery or nidus, and usually occurs near the pulmonary venous-left atrial junction. It is usually asymptomatic, and can mimic a pulmonary nodule on radiographs [24].
Pulmonary AVM

A pulmonary AVM is an abnormal communication between pulmonary artery and vein branches, without normal intervening capillaries. It may be congenital or acquired (post-trauma or infections). Hereditary hemorrhagic telangiectasis (HHT), or Rendu-Osler-Weber syndrome is an autosomal dominant condition in which up to $35 \%$ of cases have pulmonary AVMs, frequently multiple [21, 43].

Pulmonary AVMs show lower lobe predominance in $50-70 \%$ cases $[24,42]$. Lesions smaller than $2 \mathrm{~cm}$ are usually asymptomatic. Larger lesions result in right-to-left shunts, and can present with pulmonary hemorrhage or paradoxical embolization. MDCT angiography is the technique of choice for imaging [24] (Fig. 10), and management of symptomatic lesions is endovascular coil embolization.

\section{Combination of Parenchymal and Vascular Anomalies}

Pulmonary Sequestration

The word 'sequestration' (derived from Latin 'sequestrare': to separate) is defined as non-functioning lung tissue that is 


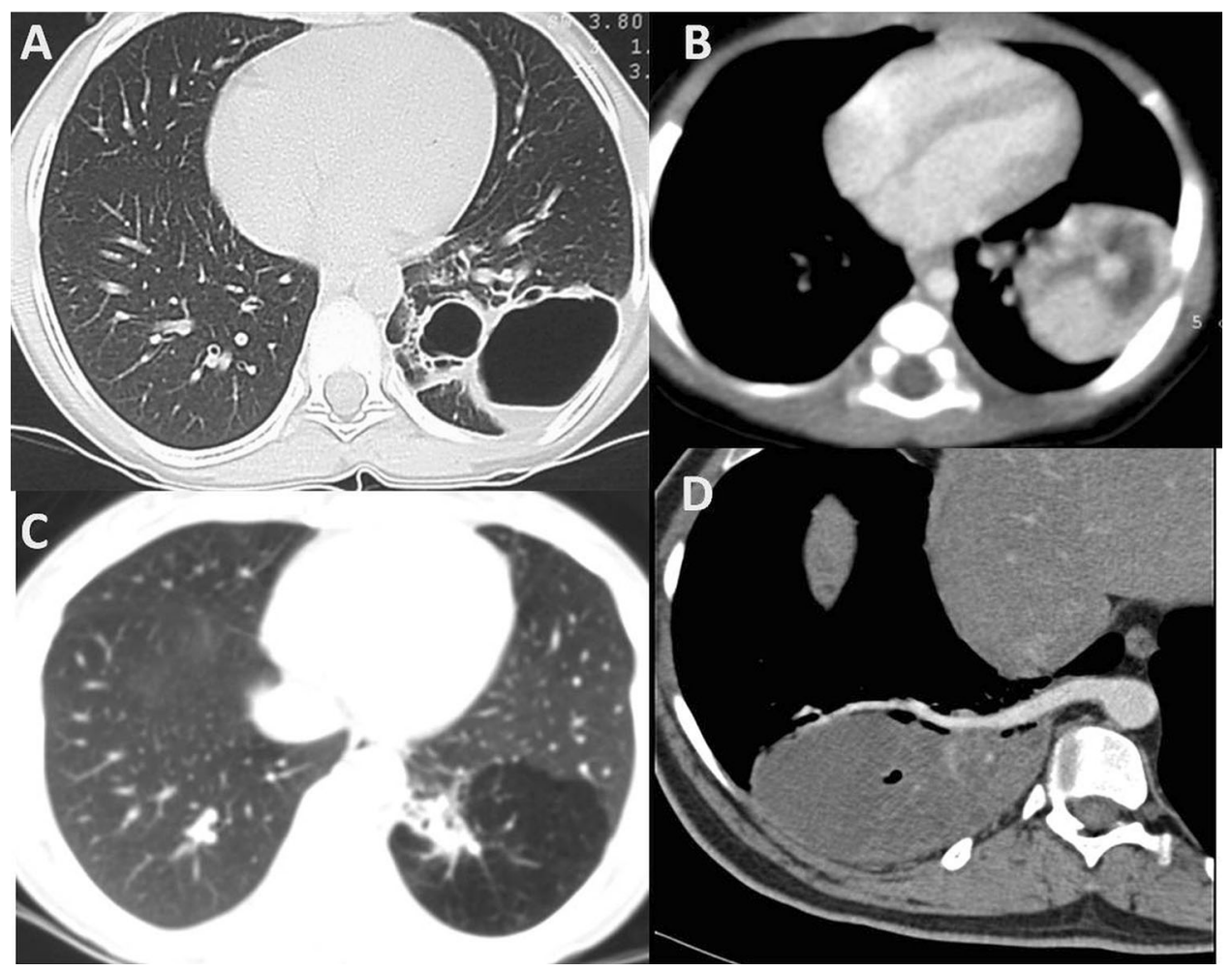

Fig. 11 CT appearances of pulmonary sequestration (four different patients). a Axial CT chest, lung window, shows a multi-cystic sequestered lung lesion in left lower lobe with presence of air, and fluid levels within. b Axial CT chest, mediastinal window, shows a heterogeneously enhancing sequestered lesion in the left lower lobe, with few non-enhancing areas, but no air within. c Incidentally detected intralobar sequestration in a young woman. Axial CT chest, lung window, reveals fibrotic lung parenchyma within the area of sequestration, with emphysematous changes in the surrounding lung. d Axial oblique image, mediastinal window, of CT chest in an adolescent male reveals sequestration within the right lower lobe, supplied by an aberrant systemic artery arising from the descending thoracic aorta not in normal continuity with the tracheobronchial tree and derives its arterial supply from systemic vessels. Classically, two forms of pulmonary sequestration-intralobar and extralobar-are described. Though intralobar sequestrations were earlier believed to be acquired lesions, increasing evidence supports a congenital origin $[44,45]$. Intralobar sequestrations (ILS) are contained within the visceral pleura of normal lung, whereas extralobar lesions have a separate pleural covering. Approximately $75 \%$ cases are intralobar, $98 \%$ cases occur within the lower lobes (left $>$ right), classically involving the posterior basal segment [46, 47]. Most ILS drain via pulmonary veins, while extralobar sequestrations (ELS) show a systemic venous drainage in $80 \%$ cases, through the azygoushemiazygous system or superior vena cava [48]. An ELS classically occurs between the left hemidiaphragm and the lower lobe (63-77\% cases), though it may occur below the diaphragm or in the mediastinum.

More than half of ELS are associated with other congenital anomalies, like congenital diaphragmatic hernia (seen in 20-30\% cases) [49]. Cases present commonly during infancy. ILS, on the other hand, usually present in adolescence or adulthood [50], often with recurrent infections.

Prenatal US may detect PS as a 'lung mass', which may be indistinguishable from CPAM on gray scale imaging. Doppler sonography is useful to depict the systemic arterial supply. For postnatal evaluation, chest radiograph is the initial imaging modality; however, findings on chest radiographs may be varied and, sometimes, subtle. PS should be suspected in all cases showing persistent radiographic opacity in the lower lobes of the lungs. MDCT can demonstrate the sequestered lesion, as well as its vascular supply (Fig. 11). The sequestration contains fibrotic and consolidated parenchyma, frequently containing cystic areas. ILS lesions may sometimes be air-filled, whereas ELS do not contain air unless it has a foregut-communication. Lung parenchyma surrounding an ILS may show emphysematous changes. The aberrant systemic artery supplying the lesion usually arises from the descending thoracic or upper abdominal aorta, and less commonly from intercostals, internal thoracic, subclavian or even 
coronary arteries. Multiple supplying vessels may be present. The most important goal of imaging is to provide a 'vascular roadmap'.

The definite treatment is surgical, though endovascular embolization has been attempted, especially for ELS [51, 52]. Thoracotomy or thoracoscopic surgery may be done, and while ELS can be managed by sequestrectomy, lobectomy is usually needed for intralobar cases.

\section{Scimitar (Hypogenetic Lung) Syndrome}

Scimitar syndrome (hypogenetic lung or venolobar syndrome) is a type of partial anomalous pulmonary venous return affecting the right lung, with associated abnormalities. The anomalous vein drains most commonly into the inferior vena cava (IVC), and less commonly into the right atrium, superior vena cava, portal vein or hepatic veins. Common associations include hypoplasia of the lung and pulmonary artery, cardiac dextroversion, and abnormal systemic arterial supply to the right lung (Fig. 12). Other congenital anomalies may be associated in $25 \%$ cases; these include atrial and ventricular septal defects, patent ductus arteriosus, tetrology of Fallot, diaphragmatic defects and horseshoe lung [21]. The name 'scimitar' (meaning curved Turkish sword) refers to the curved appearance of the anomalous vein as it courses toward the IVC.

Symptoms depend upon the degree of left to right shunting, and vary from none to heart failure in infancy. In patients with shunt ratios $>2: 1$, treatment is reconnection of the anomalous pulmonary vein to the left atrium, and embolization of the systemic arterial supply [24, 53].

\section{Nomenclature and Classification}

In 1946, Pryce coined the term 'sequestration' [54], and subsequently described three forms of intralobar sequestration [55]. Many variants were later described, and the concept of 'sequestration spectrum' was given by Sade in 1974 [56]. Since then, many terms and schemes of classification have been proposed to describe CLMs. It was recognized that

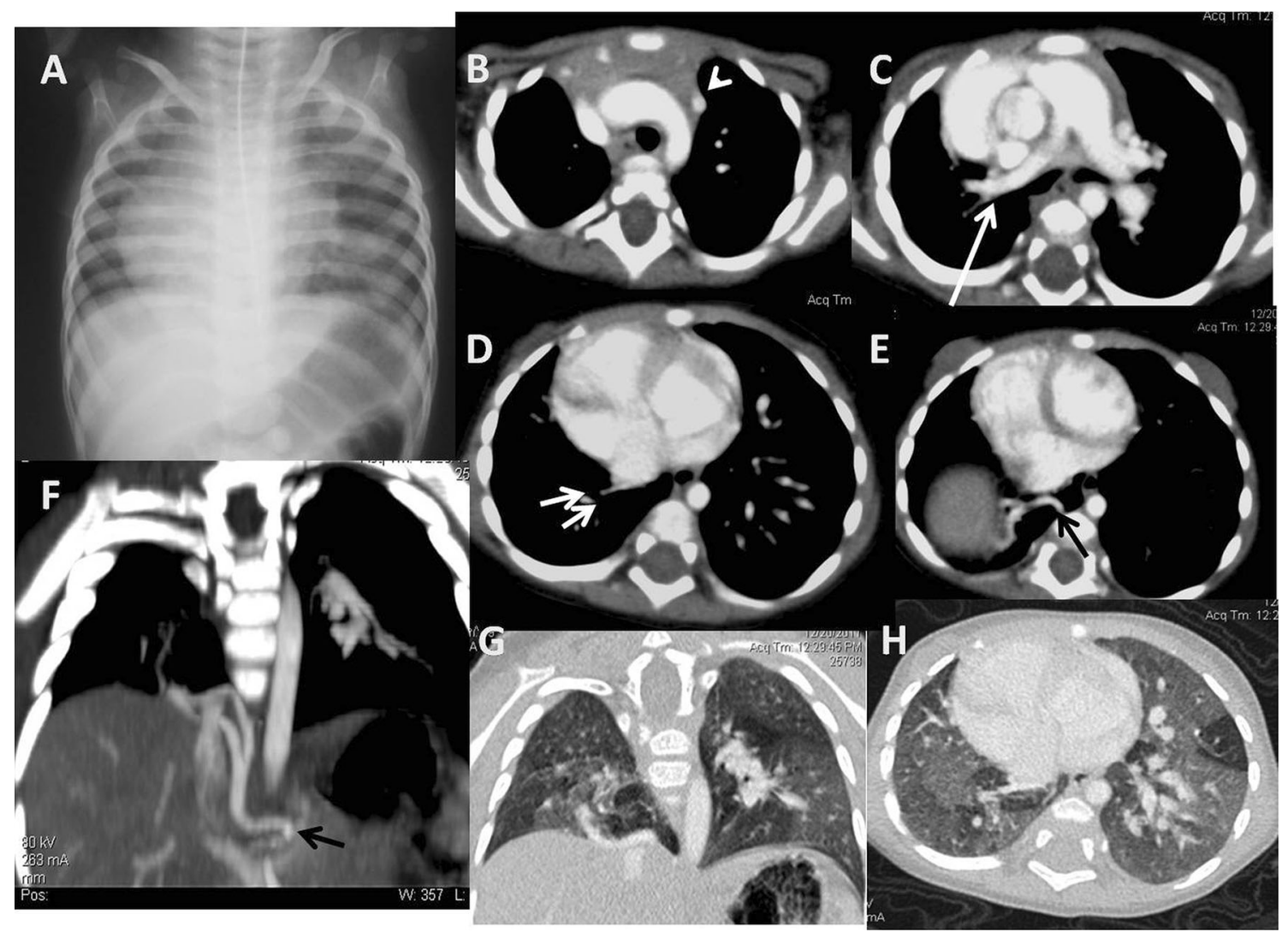

Fig. 12 An 8-month-old girl presented with recurrent chest infections since 4 months. Chest radiograph (a) reveals a small right hemithorax, with ipsilateral shift of the mediastinum. CT chest, axial sections, mediastinal window $(\mathbf{b}-\mathbf{e})$ are shown. There is a double SVC-the left brachiocephalic vein does not cross the midline and continues as left SVC (arrowhead), and a small right pulmonary artery (long arrow). Also seen is anomalous drainage of right inferior pulmonary vein into the right atrium (double arrow in d), along with an aberrant systemic artery supplying the right lower lobe (black arrow in e). Coronal image (f) depicts the origin of the anomalous systemic artery from the celiac trunk (black arrow). Coronal (g) and axial (h) lung window images show areas of mosaic attenuation. This was a case of hypogenetic lung syndrome 
lesions are often complex, show overlapping features, and involve different components-the tracheobronchial airway, arterial supply, venous drainage, lung parenchyma [57]. The term 'congenital bronchopulmonary foregut malformation' has been used for lesions with a connection with the gastrointestinal tract [58]. Langston proposed a classification system based on pathologic features. The term pulmonary 'maliosculation' ('mal'-abnormal, 'osculum'mouth) has also been proposed to describe the abnormal connections or openings of different components of the bronchopulmonary-vascular complex [57, 59].

In order to tackle the confusion regarding CLM classification, Bush highlighted the need for a more practical approach [60]. He proposed using simple language to describe 'what is actually seen', and keep clinical and pathological descriptions separate. He stressed upon a systematic approach to evaluate different components of the lesion, as well as other associated abnormalities. There is a need for radiologists and clinicians to concentrate on careful assessment and elucidation of the various components of a CLM, in order to optimize management. Pathological terms and descriptions should be avoided in radiological reporting of these cases.

\section{Conclusion}

CLM involve different components of the lung and its vascular supply. They comprise a continuum of abnormalities, with existence of 'hybrid' lesions. It is important to evaluate all components of the lesion and exclude the co-existence of other anomalies. Imaging plays a vital role in diagnosis and is especially valuable while planning surgical management.

\section{Compliance with Ethics Guidelines}

Conflict of Interest Dr. Pooja Abbey, Dr. Mahender K. Narula, and Dr. Rama Anand each declare no potential conflicts of interest.

Human and Animal Rights and Informed Consent This article does not contain any studies with human or animal subjects performed by any of the authors.

\section{References}

Papers of particular interest, published recently, have been highlighted as:

- Of importance

1. Thacker PG, Rao AG, Hill JG, Lee EY. Congenital lung anomalies in children and adults: current concepts and imaging findings. Radiol Clin N Am. 2014;52:155-81.
2. Costa Junior Ada S, Perfeito JA, Forte V. Surgical treatment of 60 patients with pulmonary malformations: what have we learned? J Bras Pneumol. 2008;34(9):661-6.

3. Panicek DM, Heitzman ER, Randall PA, et al. The continuum of pulmonary developmental anomalies. RadioGraphics. 1987;7(4):747-72.

4. Conran RM, Stocker JT. Extralobar sequestration with frequently associated congenital cystic adenomatoid malformation, type 2: report of 50 cases. Pediatr Dev Pathol. 1999;2:454-63.

5. Bratu I, Flageole H, Chen MF, et al. The multiple facets of pulmonary sequestration. J Pediatr Surg. 2001;36:784-90.

6. Heithoff KB, Sane SM, Williams HJ, et al. Bronchopulmonary foregut malformations. A unifying etiological concept. AJR. 1976;126:46-54.

7. Buntain WL, Isaacs H, Payne VC, et al. Lobar emphysema, cystic adenomatoid malformation, pulmonary sequestration, and bronchogenic cyst in infancy and childhood: a clinical group. J Pediatr Surg. 1974;9:85-93.

8. Langston C. New concepts in the pathology of congenital lung malformations. Semin Pediatr Surg. 2003;12:17-37.

9. Volpe MV, Chung E, Ulm JP, et al. Aberrant cell adhesion molecule expression in human bronchopulmonary sequestration and congenital cystic adenomatoid malformation. Am J Physiol Lung Cell Mol Physiol. 2009;297:L143-52.

10. Fromont-Hankard G, Philippe-Chomette P, Delezoide AL, et al. Glial cell-derived neurotrophic factor expression in normal human lung and congenital cystic adenomatoid malformation. Arch Pathol Lab Med. 2002;126:432-6.

11. Gonzaga S, Henriques-Coelho T, Davey M, et al. Cystic adenomatoid malformations are induced by localized FGF10 overexpression in fetal rat lung. Am J Respir Cell Mol Biol. 2008;39(3):346-55.

12. Klein JD, Turner CG, Dobson LJ, Kozakewich H, Jennings RW. Familial case of prenatally diagnosed intralobar and extralobar sequestrations with cystadenomatoid change. J Pediatr Surg. 2011;46:E27-31.

13. Crombleholme TM, Coleman B, Hedrick H, et al. Cystic adenomatoid malformation volume ratio predicts outcome in prenatally diagnosed cystic adenomatoid malformation of the lung. J Pediatr Surg. 2002;37(3):331-8.

14. Usui N, Kamata S, Sawai T, et al. Outcome predictors for infants with cystic lung disease. J Pediatr Surg. 2004;39:603-6.

15. $\cdot$ Khalek N, Johnson MP. Management of prenatally diagnosed lung lesions. Semin Pediatr Surg. 2013;22:24-9. The natural history and clinical spectrum of lung lesions diagnosed in utero is extremely variable. Management depends on prognostic factors, and has to be tailored to individual cases, keeping certain guidelines in mind. This article describes the natural history of common prenatally detected lung malformations, fetal interventions and outcomes, role of fetal surgery and perinatal management.

16. •Recio Rodriquez M, Martinez de Vega V, Cano Alonso R, Carrascoso Arranz J, Martinez Ten P, Perez Pedregosa J. MR imaging of thoracic abnormalities in the fetus. Radiographics. 2012;32:E305-21. MR imaging has become invaluable as an adjunct to sonography for the prenatal evaluation of congenital lung malformations, especially with the development of ultrafast $M R$ sequences. It guides management decisions in the antenatal and perinatal period. This article describes the normal appearances of the fetal chest on various sequences used for prenatal $M R$ imaging, along with the imaging features of common congenital lung abnormalities.

17. Daltro P, Werner H, Gasparetto TD, et al. Congenital chest malformations- a multimodality approach with emphasis on fetal MR imaging. Radiographics. 2010;30:385-95. 
18. Cannie M, Jani J, De Keyzer F, et al. Magnetic resonance imaging of the fetal lung: a pictorial essay. Eur Radiol. 2008;18(7):1364-74.

19. Paterson A. Imaging evaluation of congenital lung abnormalities in infants and children. Radiol Clin North Am. 2005;43:303-23.

20. Newman B. Congenital bronchopulmonary foregut malformations: concepts and controversies. Pediatr Radiol. 2006;36: 773-91.

21. Lee EY, Dorkin H, Vargas SO. Congenital pulmonary malformations in pediatric patients: review and update on etiology, classification and imaging findings. Radiol Clin North Am. 2011;49:921-48.

22. Lee EY, Siegel MJ. Ultrasound evaluation of pediatric chest. In: Allan PL, Baxter G, Weston M, editors. Clinical ultrasound. 3rd ed. London: Elsevier; 2011. p. 1337-55.

23. Coley BD. Pediatric chest ultrasound. Radiol Clin North Am. 2005;43(2):405-18.

24. Lee EY, Boiselle PM, Cleveland RH. Multidetector CT evaluation of congenital lung anomalies. Radiology. 2008;247(3): $632-48$.

25. Goske MJ, Applegate KE, Boyland J, et al. The image gently campaign: working together to change practice. AJR Am J Roentgenol. 2008;190(2):273-4.

26. Kim JE, Newman B. Evaluation of a radiation dose reduction strategy for pediatric chest CT. AJR Am J Roentgenol. 2010;194(5):1188-93.

27. •Wasilewska E, Lee EY, Eisenberg RL. Unilateral hyperlucent lung in children. AJR 2012;198:W400-14. A unilateral hyperlucent lung is a common radiographic appearance in a child. Its causes include abnormalities of the chest wall, airways or mediastinum, along with abnormalities of the lung parenchyma and pulmonary vasculature (including various CLM). This article highlights a systematic approach to these cases, to enable an early and accurate imaging diagnosis.

28. Kumar A, Bhatnagar V. Respiratory distress in neonates. Indian J Pediatr. 2005;72(5):425-8.

29. Mei-Zahav M, Konen O, Manson D, Langer JC. Is congenital lobar emphysema a surgical disease? J Pediatr Surg. 2006;41: 1058-61.

30. Gipson MG, Cummings KW, Hurth KM. Bronchial atresia. Radiographics. 2009;29(5):1531-5.

31. Stocker JT, Madewell JE, Drake RM. Congenital cystic adenomatoid malformation of the lung: classification and morphologic spectrum. Hum Pathol. 1977;8:155-71.

32. Stocker JT. Congenital pulmonary airway malformation-a new name for an expanded classification of congenital cystic adenomatoid malformation of the lung. Histopathology. 2002;41(Suppl 2):424-31.

33. Adzick NS, Harrison MR, Crombleholme TM, et al. Fetal lung lesions: management and outcome. Am J Obstet Gynecol. 1998;179:884-9.

34. Schrey S, Kelly EN, Langer JC, et al. Fetal thoracoamniotic shunting for large macrocystic congenital cystic adenomatoid malformations of the lung. Ultrasound Obstet Gynecol. 2012;39(5):515-20.

35. Peranteau WH, Wilson RD, Liechty KW, et al. Effect of maternal betamethasone administration on prenatal congenital cystic adenomatoid malformation growth and fetal survival. Fetal Diagn Ther. 2007;22(5):365-71.

36. Kotecha S, Barbato A, Bush A et al. Antenatal and postnatal management of congenital cystic adenomatoid malformation.Paediatr Respir Rev. 2012;13(3):162-70. Congenital cystic adenomatoid malformations (CCAMs), now known as congenital pulmonary airway malformations (CPAMs) are one of the commonest CLMs, and the management of these lesions has been subject to debate and controversy. The authors of this article have reviewed these lesions and focussed on their management, providing a set of recommendations, as well as directions for future research.

37. Kotecha S. Should asymptomatic congenital cystic adenomatous malformations be removed? The case against. Paediatr Respir Rev. 2013;14(3):171-2.

38. Laberge JM, Puligandla P, Flageole H. Asymptomatic congenital lung malformations. Semin Pediatr Surg. 2005;14:16-33.

39. Aktogu S, Yuncu G, Halilcolar H, Ermete S, Buduneli T. Bronchogenic cysts: clinico-pathological presentation and treatment. Eur Respir J. 1996;9:2017-21.

40. Biyyam DR, Chapman T, Ferguson MR, Deutsch G, Dighe MK. Congenital lung abnormalities: embryological features, prenatal diagnosis and postnatal radiologic-pathologic correlation. Radiographics. 2010;30:1721-38.

41. Mong A, Johnson AM, Kramer SS, et al. Congenital high airway obstruction syndrome: MR/US findings, effect on management, and outcome. Pediatr Radiol. 2008;38(11):1171-9.

42. Remy-Jardin M, Remy J, Mayo JR, Muller NL. Vascular anomalies of the lung. In: Remy-Jardin M, Remy J, Mayo JR, Muller NL, editors. CT angiography of the chest. Philadelphia: Lippincott Williams \& Wilkins; 2001. p. 97-114.

43. Gossage JR, Kanj G. Pulmonary arteriovenous malformation: a state of the art review. Am J Respir Crit Care Med. 1998;158:643-61.

44. Walford N, Htun K, Chen J, et al. Intralobar sequestration of the lung is a congenital anomaly: anatomopathological analysis of four cases diagnosed in fetal life. Pediatr Devel Pathol. 2003;6:314-21.

45. Liechty KW, Flake AW. Pulmonary vascular malformations. Semin Pediatr Surg. 2008;17(1):9-16.

46. Savic B, Birtel FJ, Tholen W, Funke HD, Knoche R. Lung sequestration: report of seven cases and review of 540 published cases. Thorax. 1979;34:96-101.

47. Abbey P, Das CJ, Pangtey GS, Seith A, Dutta R, Kumar A. Imaging in bronchopulmonary sequestration. J Med Imaging Radiat Oncol. 2009;53(1):22-31.

48. Rosado de Christenson ML, Frazier AA, Stocker JT, Templeton PA. Extralobar sequestration: radiologic-pathologic correlation. Radiographics. 1993;13:425-41.

49. Stocker JT. Sequestrations of the lung. Semin Diagn Pathol. 1986;3:106-21.

50. Frazier AA, Rosado de Christenson ML, Stocker JT, Temleton PA. Intralobar sequestration: radiologic- pathologic correlation. Radiographics. 1997;17:725-45.

51. Cho MJ, Kim DY, Kim SC, Kim KS, Kim EA, Lee BS. Embolization versus surgical resection of pulmonary sequestration: clinical experiences with a thoracoscopic approach. J Pediatr Surg. 2012;47(12):2228-33.

52. Curros F, Chigot V, Emond S, Sayegh N, Revillon Y, Scheinman $\mathrm{P}$, Lebourgeois M, Brunelle F. Role of embolisation in the treatment of bronchopulmonary sequestration. Pediatr Radiol. 2000;30(11):769-73.

53. Donnelly LF. Cardiac. In: Diagnostic imaging pediatrics. Salt Lake City: Amirsys; 2005. p. 98-101.

54. Pryce DM. Lower accessory pulmonary artery with intralobar sequestration of lung: report of seven cases. J Pathol Bacteriol. 1946;58(3):457-67.

55. Pryce DM, Holmes Sellors T, Blair LG. Intralobar sequestration of lung associated with an abnormal pulmonary artery. Br J Surg. 1947;35:18-29.

56. Sade RM, Clouse M, Ellis FH. The spectrum of pulmonary sequestration. Ann Thorac Surg. 1974;18:644-55.

57. Clements BS, Warner JO. Pulmonary sequestration and related congenital bronchopulmonary-vascular malformations: nomenclature and classification based on anatomical and embryological considerations. Thorax. 1987;42(6):401-8. 
58. Gerle RD, Jaretzki A III, Ashley CA, et al. Congenital bronchopulmonary-foregut malformation: pulmonary sequestration communicating with the gastrointestinal tract. N Engl J Med. 1968;278:1413-9.

59. Lee ML, Lue HC, Chiu Ieta $1 \mathrm{~S}$ et al. A systematic classification of the congenital bronchopulmonary vascular malformations: dysmorphogeneses of the primitive foregut system and the primitive aortic arch system. Yonsei Med J. 2008;49(1):90-102. 60. Bush A. Congenital lung disease: a plea for clear thinking and clear nomenclature. Pediatr Pulmonol. 2001;32:328-37. 